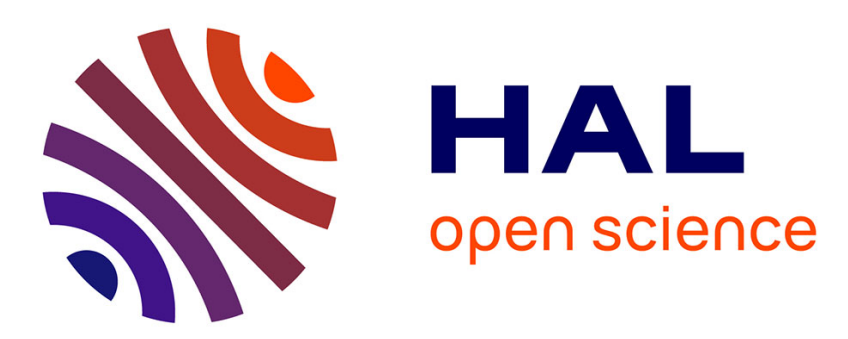

\title{
Determination of the Exact Microporous Volume and BET Surface Area in Hierarchical ZSM-5
}

\author{
Isabelle Batonneau-Gener, Alexander Sachse
}

\section{To cite this version:}

Isabelle Batonneau-Gener, Alexander Sachse. Determination of the Exact Microporous Volume and BET Surface Area in Hierarchical ZSM-5. Journal of Physical Chemistry C, 2019, 123 (7), pp.42354242. 10.1021/acs.jpcc.8b11524 . hal-02352124

\section{HAL Id: hal-02352124 \\ https://hal.science/hal-02352124}

Submitted on 6 Nov 2019

HAL is a multi-disciplinary open access archive for the deposit and dissemination of scientific research documents, whether they are published or not. The documents may come from teaching and research institutions in France or abroad, or from public or private research centers.
L'archive ouverte pluridisciplinaire HAL, est destinée au dépôt et à la diffusion de documents scientifiques de niveau recherche, publiés ou non, émanant des établissements d'enseignement et de recherche français ou étrangers, des laboratoires publics ou privés. 


\section{Determination of the Exact Microporous}

\section{Volume and BET Surface Area in}

\section{Hierarchical ZSM-5}

Isabelle Batonneau-Gener, ${ }^{*}$ Alexander Sachse ${ }^{*}$

Université de Poitiers, Institut de Chimie des Milieux et Matériaux de Poitiers (IC2MP) -

UMR 7285 CNRS, UFR SFA, Bât. B27, 4 rue Michel Brunet, TSA 51106, 86073 Poitiers

Cedex 9 - France

*corresponding authors: alexander.sachse@univ-poitiers.fr, isabelle.batonneau@univ-

poitiers.fr 


\begin{abstract}
The determination of the exact microporous volume in hierarchical zeolites is of crucial importance as it allows for the accurate description of these textural properties. Standard physisorption procedures based on recording nitrogen and argon adsorption isotherms prove for major limitations for the determination of the amount of micropores and of the BET surface area in such hierarchical systems. We present two methodologies for the precise determination of the microporous volume and BET surface area based on $(i)$ the volume difference in nitrogen physisorption isotherms at $77 \mathrm{~K}$ by $n$-nonane preadsorption and (ii) the interpretation of $n$-hexane adsorption isotherms measured at $298 \mathrm{~K}$. As far as the $n$-nonane preadsorption technique is concerns, it allows to decouple the adsorption in the micropores and that on the external (and mesopore) surface, hence allowing to determine the micropore volume, monolayercapacity and amount of occulted mesopores. In $n$-hexane physisorption, due to the strong confinement of the sorbate in micropores and the less favored moleculesurface interaction of $n$-hexane the micropore filling is independently observed at low relative pressures. The adsorption on the external surface, which is at the origin of mesopore filling, occurs only once micropores are completely filled-up with the adsorbate. A set of mechanical mixtures of purely microporous ZSM-5 and mesoporous MCM-41 has allowed to assess the accurate determination of microporous volume by these strategies. Whilst the $n$-nonane preadsorption strategy is time consuming, the measurement of $n$-hexane isotherms at $298 \mathrm{~K}$ is easy and could hence be implemented as standard technique for the accurate determination of textural properties of complex, hierarchical systems.
\end{abstract}




\section{Introduction}

Zeolites are a family of crystalline materials with well defined microporous structures. Besides strong acidity, these aluminosilicates feature molecular shape selectivity and confinement effects due to their porous topologies, ${ }^{1}$ which explain their key role in many catalytic processes. Yet, zeolites present important limitations, particularly for the development of new heterogeneous catalytic systems, resulting from their extended diffusion path length, which leads to low effectiveness factors. ${ }^{2}$ With the aim to shortening the diffusion path length in zeolites the development of secondary porosity within crystals has been put forward as promising approach. ${ }^{3}$ During the past 20 years an impressive number of synthetic strategies have been developed that allow to conceive zeolites with porosities at different length scales. ${ }^{4}$

ZSM-5 is by far the most versatile zeolite used in industrial catalytic applications and is extensively employed as catalytic component in alkylation, isomerization, selective cracking, etherification, esterification, hydration, disproportionation and amination processes. ${ }^{5}$ High silica ZSM-5 is majorly employed in these procedures, due to its cost efficient preparation which does not require the use of structure directing agents. ${ }^{6}$ The development of tailored hierarchization techniques for ZSM-5 prevails as one of the hot topics in zeolite science. ${ }^{7}$

With the aim to assess the efficiency of particular hierarchization strategies, micro- and mesoporous volumes are typically compared with those of pristine zeolites. Textural characterization based on nitrogen or argon physisorption at 77 and $87 \mathrm{~K}$, respectively, have become standard procedures. ${ }^{8,9}$ Yet, the determination of the microporous volume in hierarchical zeolites is far from being evident. ${ }^{10}$ Indeed, recording such adsorption isotherms present strong limitations for the exact determination of the microporous volume. ${ }^{11}$ This issue results from the strong sorbent-surface interactions, which hence do not allow to distinguish the micropore filling from the formation of the sorbate monolayer, which is at the origin of 
the mesopore filling in the low pressure range of nitrogen and argon physisorption isotherms. A commonly used operation from which microporous volume are routinely derived from such adsorption isotherms is the $t$-plot method. ${ }^{12,13}$ The $t$-curve is obtained through comparing the thickness of the adsorbate layer on a flat surface in function of the relative pressure of the adsorbate and temperature of a non-porous reference material of similar composition to the isotherm of the studied material. ${ }^{14}$ This methodology yet presents sever limitations that importantly reduce the accuracy of the estimated microporous volume, as: $(i)$ the microporous volume varies importantly with the pressure range that is arbitrarily chosen to set the linear regressions to determine microporous volume and (ii) the $t$-plot method does not take into consideration the effect of pore curvature on the thickness of the adsorbed film. ${ }^{11,15}$ Hence, the use of the $t$-method leads to important misinterpretations of the real microporous volume. Galarneau and co-workers explored the validity of the $t$-plot method for hierarchical FAU zeolites and found that as function of the hierarchization degree the method importantly underestimates the microporous volume to up to $40 \%{ }^{11}$ In order to adjust the $t$-curve, the authors proposed an abacus that rectifies the plot in order to deduce the true microporous volumes.

Though this methodology allows to correct the microporous volume in hierarchical FAU it is not suited for ZSM-5. In high silica ZSM-5 the nitrogen and argon physisorption isotherms at 77 and $87 \mathrm{~K}$ present a step with hysteresis in the low pressure range centered at relative pressures of $0.1-0.2$ and $3 \cdot 10^{-4}-2 \cdot 10^{-3}$, respectively. ${ }^{16}$ The nature of this adsorption step has firstly been described to result from a phase transition of the monoclinic MFI form into its orthorhombic structure. ${ }^{17}$ More recently the appearance of the adsorption step has been related to a phase transition of the adsorbate from a "disordered phase" to a "lattice fluid-like phase". ${ }^{18}$ The adsorption step in the low pressure range has important consequences on the determination of the microporous volume by the $t$-plot method as a deviation of the linear 
behavior falls into the fitting range, which is usually taken to deduce the microporous volume. In this case, the $t$-plot is generally fitted at a higher range of thicknesses of the sorbate layer (i.e. 0.6 and $0.8 \mathrm{~nm}$ ). Yet, this approach is not feasible for hierarchical ZSM-5 as this range already corresponds to the adsorption of the sorbate in mesopores.

In this contribution we present two strategies that allow for the determination of the exact microporous volume and monolayercapacity in hierarchical ZSM-5 zeolites based on (i) assessing the volume difference in nitrogen physisorption isotherms at $77 \mathrm{~K}$ by $n$-nonane preadsorption and (ii) the recording of $n$-hexane isotherms at $298 \mathrm{~K}$.

\section{Experimental methods}

\subsection{Materials}

Ludox-AS-30 (Aldrich), $\mathrm{NaOH}$ (Aldrich), $\mathrm{Al}$ (Merck), $\mathrm{NH}_{4} \mathrm{OH}$ (30\%, Aldrich), n-nonane (ACROS), $n$-hexane (Aldrich), tetraethylorthosilicate (TEOS, Aldrich), $n$ Cetyltrimethylammonium bromide (CTAB, Aldrich), sodiumaluminate (Aldrich), tetrapropylammonium bromide (TPABr, Aldrich), tetrabutylammonium hydroxide (40\%, TBAOH), tetrapropylammonium hydroxide (20\%, Aldrich), aluminiumnitrate nonahydrate (Aldrich) were purchased and used as received.

\subsection{Synthesis of materials}

\subsubsection{MCM-41 (MO)}

$1.00 \mathrm{~g}$ of CTAB was dissolved in $450 \mathrm{~mL}$ of distilled water in a $1 \mathrm{~L}$ polyprolpylene reactor fitted with a stirring bar. $3.50 \mathrm{~mL}$ of $\mathrm{NaOH}(2.00 \mathrm{M}$ aqueous solution) was added. The temperature of the solution was adjusted to $353 \mathrm{~K}$, through placing the reactor in an oil bath. 5 $\mathrm{mL}$ of TEOS was added dropwise to the basic CTAB solution. The molar composition of the 
synthesis mixture was $0.90 \mathrm{TEOS}: 0.28 \mathrm{NaOH}: 0.11 \mathrm{CTAB}: 1000 \mathrm{H}_{2} \mathrm{O}$. A white precipitate started to form within 5 minutes after addition of TEOS. The mixture was stirred at $353 \mathrm{~K}$ for $2 \mathrm{~h}$ and subsequently centrifuged $(10000 \mathrm{rpm}, 10 \mathrm{~min})$ followed by three washing cycles with distilled water, dried at $353 \mathrm{~K}$ for $12 \mathrm{~h}$ and calcined at $823 \mathrm{~K}$ for $8 \mathrm{~h}$ under air. The sample was named M0.

\subsubsection{ZSM-5 (M100)}

$23.72 \mathrm{~g}$ of ammonia (30\%) were dissolved in $16.47 \mathrm{~g}$ of distilled water in a polypropylene reactor under stirring. $0.42 \mathrm{~g}$ of sodiumaluminate and $7.21 \mathrm{~g}$ TPABr were subsequently added and dissolved in the basic solution. $40 \mathrm{~g}$ of Ludox-AS-30 were added and vigorously stirred during 10 min. The molar composition of the synthesis was 59SiO $2: 1.5 \mathrm{NaAlO}_{2}: 60 \mathrm{NH}_{4} \mathrm{OH}: 8 \mathrm{TPABr}: 1000 \mathrm{H}_{2} \mathrm{O}$. The mixture was transferred to a stainless steel autoclave fitted with a Teflon jacket. The sealed autoclave was placed in an oven at 453 $\mathrm{K}$ during $72 \mathrm{~h}$. The autoclave was allowed to cool to RT and the mixture was filtered. The white powder was washed with $400 \mathrm{~mL}$ distilled water, dried at $353 \mathrm{~K}$ during $12 \mathrm{~h}$ and calcined under air at $823 \mathrm{~K}$ for $8 \mathrm{~h}$. The $\mathrm{Si} / \mathrm{Al}$ ratio of the sample is 40 . The sample was named M100.

\subsubsection{Mechanical mixtures (M10, M25, M50, M75, M90)}

Mechanical mixtures were prepared by combining M0 and M100 in different wt\%. Table 1 resumes the theoretical microporous volume for the mixtures M10, M25, M50, M75, M90, in which the number indicates the percentage of microporosity. 
Table 1. Microporous volumes of M0 and M100 estimated through the $t$-method on $\mathrm{N}_{2}$ adsorption isotherms at $77 \mathrm{~K}$ and deduced theoretical microporous volume of mechanical mixtures M10, M25, M50, M75, M90.

\begin{tabular}{lc}
\hline M & $\mathrm{V}_{\text {micro }}(t$-plot $) \mathrm{cm}^{3} \mathrm{~g}^{-1}$ \\
\hline M0 & 0 \\
M10 & 0.017 \\
M25 & 0.041 \\
M50 & 0.083 \\
M75 & 0.124 \\
M90 & 0.149 \\
M100 & 0.165 \\
\hline
\end{tabular}

\subsubsection{Hierarchical ZSM-5 (HM-0.2, HM-0.6)}

$30 \mathrm{~mL}$ of aqueous $\mathrm{NaOH}$ solution containing $2 \mathrm{~mL}$ of $\mathrm{TBAOH}(40 \%$ in water) were placed in a propylene reactor with stir bar and heated to $343 \mathrm{~K}$ in an oil bath. $1 \mathrm{~g}$ of the atop synthesized ZSM-5 (M100) was added and the mixture was stirred for $1 \mathrm{~h}$ at $343 \mathrm{~K}$. The reactions were quenched in an ice bath, filtered, washed with $100 \mathrm{~mL}$ distilled water, dried at $353 \mathrm{~K}$ for $12 \mathrm{~h}$ and calcined in air at $823 \mathrm{~K}$ for $12 \mathrm{~h}$. The achieved samples were named HM-X, in which $\mathrm{X}$ stands for the molar concentration of the $\mathrm{NaOH}$ solution.

\subsubsection{ZSM-5 nanoboxes (NBM)}

Nano-ZSM-5 was synthesized through the preparation of two solutions. Solution 1 was prepared in a polypropylene reactor with stirring bar in which $10 \mathrm{~mL}$ of TPAOH were diluted in $6 \mathrm{~mL}$ of distilled water. $16.64 \mathrm{~g}$ of TEOS were subsequently added. The mixture was heated to $353 \mathrm{~K}$ and stirred for $24 \mathrm{~h}$ at this temperature. Solution 2 was prepared through dissolving $1 \mathrm{~g}$ of aluminium nitrate nonahydrate and $0.53 \mathrm{~g}$ of $\mathrm{NaOH}$ in $5.32 \mathrm{~g}$ of distilled water. Solution 1 was added to solution 2 at RT under constant stirring. The molar composition of the mixture was: 29.85TEOS:7.35TPAOH:359 $\mathrm{H}_{2} \mathrm{O}: 1 \mathrm{Al}\left(\mathrm{NO}_{3}\right)_{3}: 5 \mathrm{H}_{2} \mathrm{O}$. A white suspension immediately formed. 
This was transferred to a stainless steel autoclave lined with a Teflon jacket. The sealed autoclave was placed in an oven at $443 \mathrm{~K}$ for $24 \mathrm{~h}$. After cooling to RT, the synthesis mixture was centrifuged, and the remaining solid washed three times with distilled water, dried at $353 \mathrm{~K}$ for $12 \mathrm{~h}$ and calcined at $823 \mathrm{~K}$ for $8 \mathrm{~h}$. The Si/Al ratio of the nano-ZSM-5 is 32 . The nanoboxes were obtained by combining $1 \mathrm{~g}$ of the nano-ZSM-5 with $15 \mathrm{~mL}$ of an aqueous $\mathrm{NaOH}$ solution $(0.1 \mathrm{M})$ and stirred at $323 \mathrm{~K}$ in an oil bath for $15 \mathrm{~h}$. The mixture was centrifuged, washed three times with distilled water, dried at $353 \mathrm{~K}$ for $12 \mathrm{~h}$ and calcined in air at $823 \mathrm{~K}$ for $8 \mathrm{~h}$. The obtained ZSM-5 nanoboxes were named NBM.

\subsubsection{Self-pillared MFI nanosheets (SPM)}

$17.85 \mathrm{~mL}$ of TEOS were placed in polypropylene reactor with a stir bar, and $15.75 \mathrm{~mL}$ of TBAOH (40\%) were drop-wise added with a syringe under vigorous stirring. The molar composition of the mixture was 1TEOS:0.3TBAOH:10 $\mathrm{H}_{2} \mathrm{O}$. The mixture was stirred for $24 \mathrm{~h}$ at RT and then transferred to a stainless steel autoclave fitted with a Teflon jacket. The sealed autoclave was placed in an oven at $393 \mathrm{~K}$ for 5 days. After cooling to RT, the synthesis mixture was centrifuged, and the remaining solid washed three times with distilled water, dried at $353 \mathrm{~K}$ for $12 \mathrm{~h}$ and calcined at $823 \mathrm{~K}$ for $12 \mathrm{~h}$. The resulting material was named SPM.

\subsubsection{Synthesis of the non-porous silica (NPM) for the t-plot reference isotherm}

$75 \mathrm{~mL}$ of $\mathrm{NH}_{4} \mathrm{OH}$ were diluted in $440 \mathrm{~mL}$ ethanol (absolute) in a $1 \mathrm{~L}$ glass flask equipped with stirring bar. $32.5 \mathrm{~mL}$ TEOS were added at once. The molar composition was 1TEOS:4.36 $\mathrm{NH}_{4} \mathrm{OH}: 186.3 \mathrm{H}_{2} \mathrm{O}$. The solution turns turbid within 5 min. Stirring was continued at RT for $1 \mathrm{~h}$. The mixture was centrifuged, and the remaining solid washed three times with distilled water, dried at $353 \mathrm{~K}$ for $12 \mathrm{~h}$ and calcined at $823 \mathrm{~K}$ for $12 \mathrm{~h}$. 


\subsection{Physisorption experiments}

\subsubsection{Nitrogen physisorption}

$\mathrm{N}_{2}$ physisorption isotherms were recorded at $77 \mathrm{~K}$ using a Micromeritics 3FLEX instrument. Before analysis, all samples were outgassed under secondary vacuum for $12 \mathrm{~h}$ at $623 \mathrm{~K}$ (for calcined samples) and at RT (for $n$-nonane preadsorbed samples). Surface areas were obtained by applying the Brunauer-Emmett-Teller (BET) equation on the linear zone of the BET plot. The $t$-plot was achieved as stated in the ESI.

\subsection{2 n-Nonane preadsorption}

Samples ( 40 mg) were placed in a SETARAM microbalance and out-gassed under secondary vacuum at $573 \mathrm{~K}$ for $10 \mathrm{~h}$ and cooled to $298 \mathrm{~K}$. The samples were exposed to $n$ nonane vapors for $2 \mathrm{~h}$ and then evacuated under secondary vacuum at $298 \mathrm{~K}$ until mass stabilization. The samples were then transferred to a Micromeritics 3FLEX instrument. After a second out-gassing at $298 \mathrm{~K}$ under secondary vacuum, the nitrogen physisorption isotherms were recorded at $77 \mathrm{~K}$.

\subsection{3 n-Hexane physisorption}

$n$-Hexane adsorption isotherms were performed at $298 \mathrm{~K}$ by thermogravimetry using a SETARAM microbalance. The samples (approximately $20 \mathrm{mg}$ ) were out-gassed under secondary vacuum at $573 \mathrm{~K}$ for $10 \mathrm{~h}$ and cooled to $298 \mathrm{~K}$ prior to the sorption measurements. The sorbate pressure was then increased step by step (interval of 0.005 mbar for low relative pressures) in order to obtain the entire adsorption isotherm. For each uptake, the mass change was recorded as function of time. After mass stabilization, the amount of adsorbate was calculated from the mass reached at equilibrium and plotted against the equilibrium pressure. 


\subsection{Materials characterization}

Transmission Electronic Microscopy (TEM) coupled with Energy Dispersive X-ray Spectroscopy (EDXS) were performed over selected samples, using a JEOL 2100 instrument (operated at $200 \mathrm{kV}$ with $\mathrm{a} \mathrm{LaB}_{6}$ source and equipped with a Gatan Ultra scan camera), (Figure S1). Powder diffractograms were collected using a PANalytical Empyrean X-ray diffractometer using $\mathrm{CuK} \alpha$ radiation $(1.54059 \AA)$ ), for $2 \theta$ ranging from $5^{\circ}$ to $40^{\circ}$. Scan speed was fixed at $0.008^{\circ} \min ^{-1}$ (Figure S2). The elemental $\mathrm{Si} / \mathrm{Al}$ ratios were determined by using ICP-OES analysis, using a Perkin Elmer Optima 2000 DV instrument.

\section{Results and Discussion}

\subsection{Limitations of nitrogen physisorption isotherms at $77 \mathrm{~K}$ for the determination of microporous volume}

A set of mechanical mixtures was prepared from ZSM-5 (M100) and MCM-41 (M0). The nitrogen adsorption and desorption isotherms were recorded on these samples (Figure S3). The nitrogen adsorption and desorption isotherms of pure ZSM-5 (M100), MCM-41 (M0) and the ZSM-5/MCM-41=50/50 mechanical mixture (M50) indicate that condensation in micropores occurs concomitantly in the same relative pressure range as the formation of the sorbate monolayer (Figure 1a). Hence, the microporous volume cannot directly be deduced from the adsorption isotherms. The $t$-plot method has been put forward as key strategy for the diligent description of microporous volume from $\mathrm{N}_{2}$ physisorption isothermes. ${ }^{12} \mathrm{We}$ constructed the $t$-plot for M0, M50 and M100 using a non-porous silica as standard (Figure 1b). The $t$-plot of M100 was fitted in the $t$-range of $0.5-0.6 \mathrm{~nm}$, which allows to deduce a microporous volume of $0.165 \mathrm{~cm}^{3} \mathrm{~g}^{-1}$ from the intercept of the regression line with the ordinate. It is to note that fitting at lower values of thickness is not viable due to the deviation of the linear behavior (step in the adsorption isotherms at relative pressure of 0.15 ). For M0 
the $t$-plot was fitted in the $t$-range of $0.35-0.45 \mathrm{~nm}$. As expected for a purely mesoporous material this linear regression intercepts the ordinate at zero. For the mechanical mixture M50, the fitting of the $t$-plot is difficult. Indeed, the same fitting range as for M100 is not viable as a strong deviation of the linear behavior is observed, due to the capillary condensation in the mesopores. It is to note that the alpha-S method ${ }^{19}$ leads to the same difficulties in the determination of the microporous volume. The exact determination in of the microporous volume in mechanical mixtures of microporous ZSM-5 and mesoporous MCM41 is hence strongly limited by nitrogen physisorption. The same issue occurs for hierarchical ZSM-5
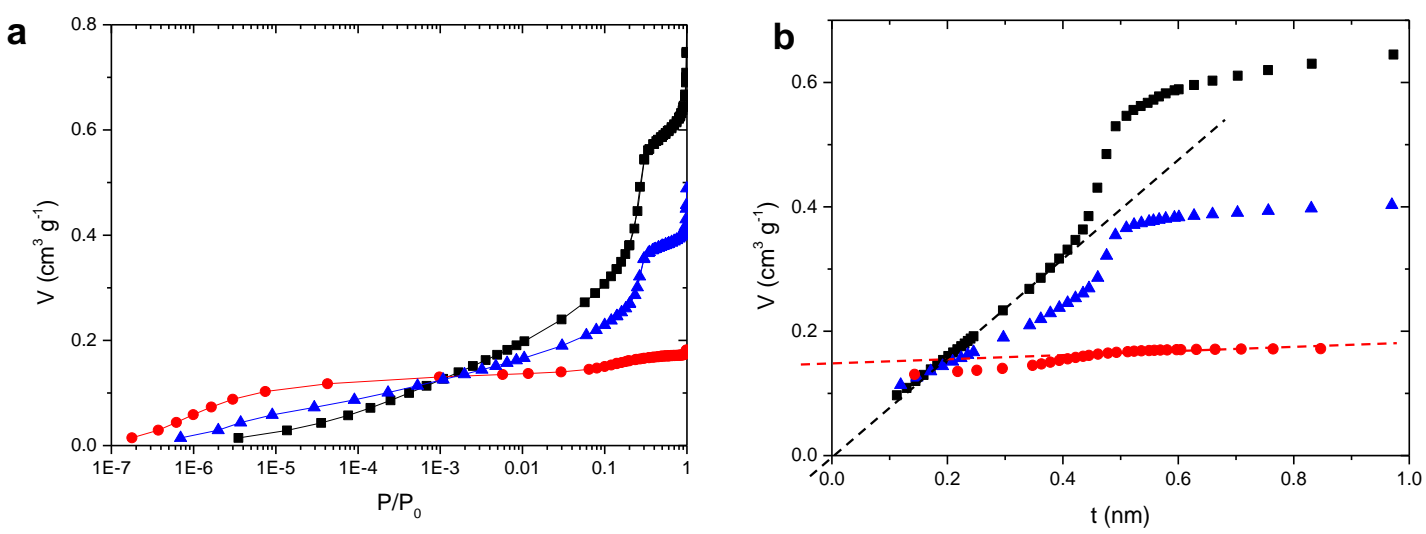

Figure 1. Nitrogen adsorption isotherms at $77 \mathrm{~K}$ (a) and $t$-plots (b) of M0, M50 and M100.

\section{$3.2 n$-Nonane preadsorption followed by nitrogen physisorption at $77 \mathrm{~K}$}

The $n$-nonane preadsorption methodology was introduced by Gregg and Langford ${ }^{20}$ and has extensively been applied for the determination of the microporous volume in activated carbons. $^{21}$ As far as zeolites are concerned the $n$-nonane preadsorption technique has been evaluated for MFI type zeolites. ${ }^{22}$ The $n$-nonane preadsorption methodology relies on the complete adsorption of the sorbent in the micropores of a sample. Through outgassing at low temperatures (at RT and below) the $n$-nonane is removed from the external surface of the 
sample but not from the micropores. $n$-Nonane has an important physisorption energy in micropores, which consequently results in a high energy barrier for its desorption. Indeed, the preadsorbed $n$-nonane is only removed from such micropores at elevated temperatures. Thus, recording nitrogen physisorption isotherm at $77 \mathrm{~K}$ on a $n$-nonane preadsorbed materials will allow to observe the adsorption of nitrogen only on the external surface and in accessible mesopores. The difference in the nitrogen adsorption volume of the sample before and after $n$ nonane preadsorption will hence correspond to the microporous volume. In order to verify this, nitrogen adsorption and desorption isotherms were measured at $77 \mathrm{~K}$ on mechanical mixtures M0, M10, M25, M50, M75, M90, M100 before and after n-nonane preadsorption (Figures 2a and 2b). From the difference of the nitrogen adsorbed volume at the relative pressure of 0.4 , the microporous volume was determined. Here from the microporous volume of M100 has been calculated to be $0.160 \mathrm{~cm}^{3} \mathrm{~g}^{-1}$, which is slightly lower than the microporous volume achieved through the $t$-plot method (Table 1). It is reminded that the $t$-plot method takes into consideration several assumptions, which leads to erroneous values of the true micropores volume even for purely microporous zeolites. ${ }^{11,12}$ Hence, the microporous volume determined by the $n$-nonane preadsorption is for the following taken as the true microporous volume. The microporous volumes determined for the mechanical mixtures correspond to those theoretically expected (Figure 2c). Additionally, we determined the amount of $n$ nonane adsorbed in the samples, through outgassing the $n$-nonane preadsorbed samples at $623 \mathrm{~K}$. The $\mathrm{wt} \%$ of $n$-nonane in the sample is proportional to the microporous volume (Figure 5S). 

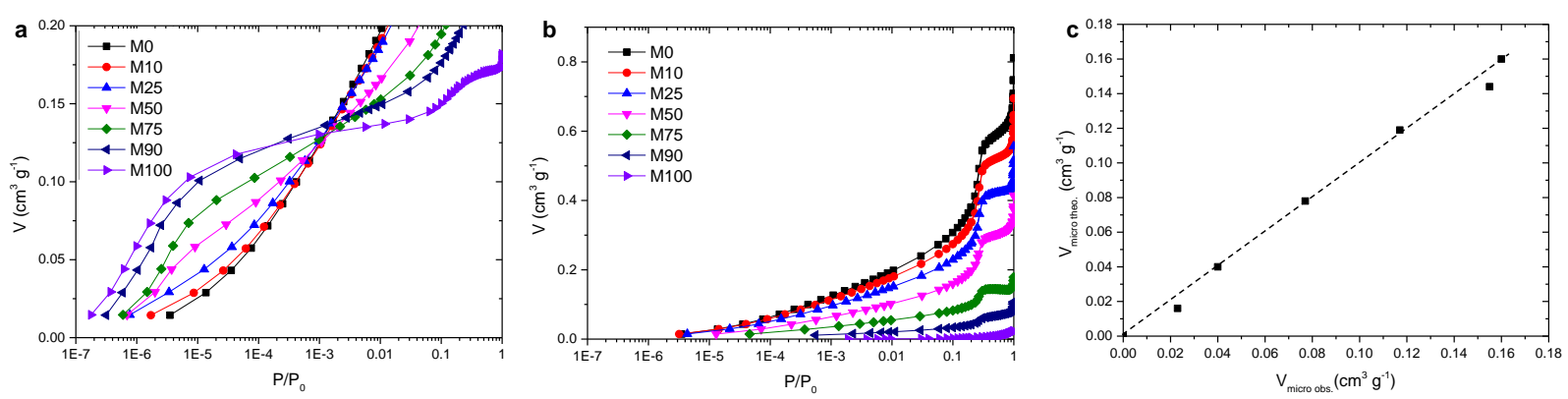

Figure 2. Nitrogen adsorption isotherms at $77 \mathrm{~K}$ before (a) and after $n$-nonane adsorption (b) for M0, M10, M25, M50, M75, M90, M100. c) The theoretical microporous volume as a function of the calculated microporous volume through the $n$-nonane preadsorption method.

The $n$-nonane preadsorption on hierarchical ZSM-5 samples has furthermore the advantage, next to the accurate determination of the micropores volume, to allow for assessing the amount of occulted mesopores (i.e. mesopores that are only accessible via the micropores). Indeed, for the ZSM-5 nanoboxes (NBM) in which the interior of the zeolite crystal is hollow (Figure S1), the $n$-nonane preadsorption allows probing the volume through the difference in the observed volume of the hysteresis at values of $\mathrm{P} / \mathrm{P}_{0}=0.5$, which accounts for NBM to $0.07 \mathrm{~cm}^{3} \mathrm{~g}^{-1}$ (Figure 3a). In the case of the self pillared zeolite (SPM) the shape of the hysteresis is identical before and after $n$-nonane adsorption, which indicates the absence of occulted mesopores in this sample (Figure 3b). For NBM and SPM the microporous volume were calculated to be 0.126 and $0.095 \mathrm{~cm}^{3} \mathrm{~g}^{-1}$, respectively. 

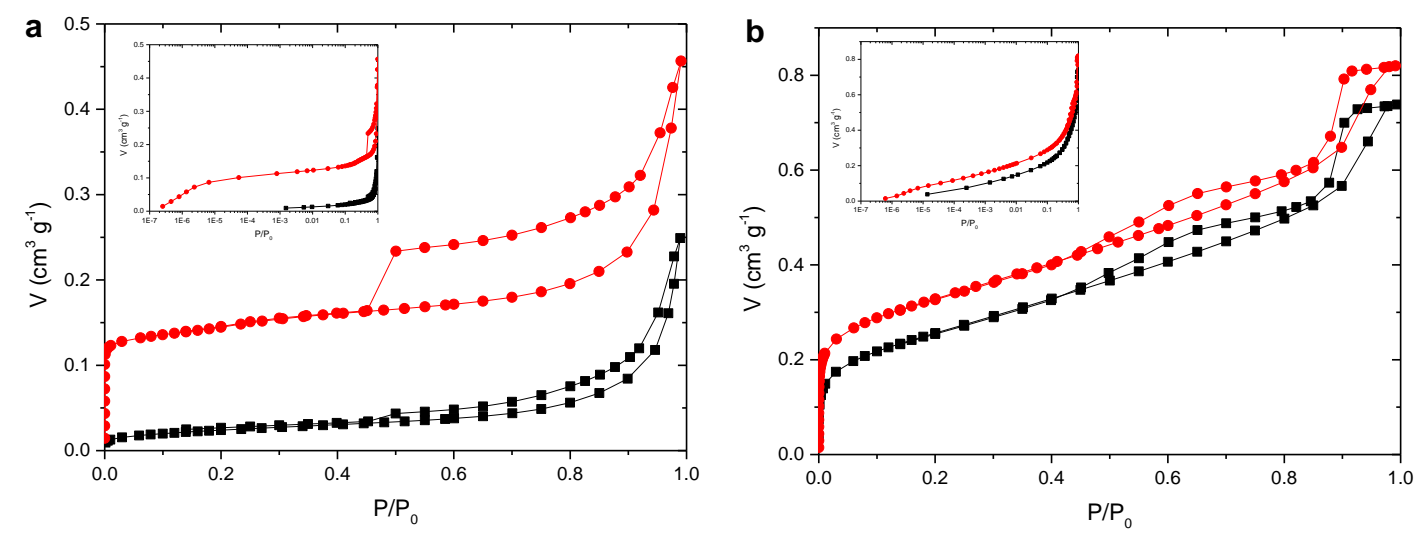

Figure 3. Nitrogen adsorption and desorption isotherms at $77 \mathrm{~K}$ before (red) and after (black) $n$-nonane preadsorption for NBM (a) and SPM (b). The insets represent the isotherms with logarithmic $\mathrm{P} / \mathrm{P}_{0}$ scale.

\subsection{Calculation of the exact monolayercapacity through the BET theory}

The standardized method for calculating a samples surface area from nitrogen and argon physisorption isotherms is the BET equation. ${ }^{23}$ The strategy is based on calculating the volume occupied by one sorbent monolayer (i.e. the monolayercapacity). This value is then proportional to the surface. Yet, in the case the sample contains micropores, the nitrogen (or argon) adsorption does not lead to the formation of a well closed packed liquid layer in the micropores surface. In this case the deduced monolayercapacity is inexact and leads to erroneous values of the surface area. $^{24}$ Despite, most contributions related with the development of hierarchical zeolites present BET surface area as important key parameter to deduce textural characteristics of modified zeolites.

As atop verified, the $n$-nonane preadsorption method allows for decoupling the adsorption in micropores and the adsorption on the external and mesopore surface. Based on this observation the true BET surface area was calculated for the mechanical mixtures M0, M10, M25, M50, M75, M90, M100. With increasing amount of microporosity in the samples the error of the apparent and the true BET surface area increases strongly (Figure 4). Indeed, for 
the pure ZSM-5 (M100) the BET surface area obtained from standard nitrogen physisorption experiments is $431 \mathrm{~m}^{2} \mathrm{~g}^{-1}$; a value which exceeds the actual surface area by $419 \mathrm{~m}^{2} \mathrm{~g}^{-1}$ (Table 2).

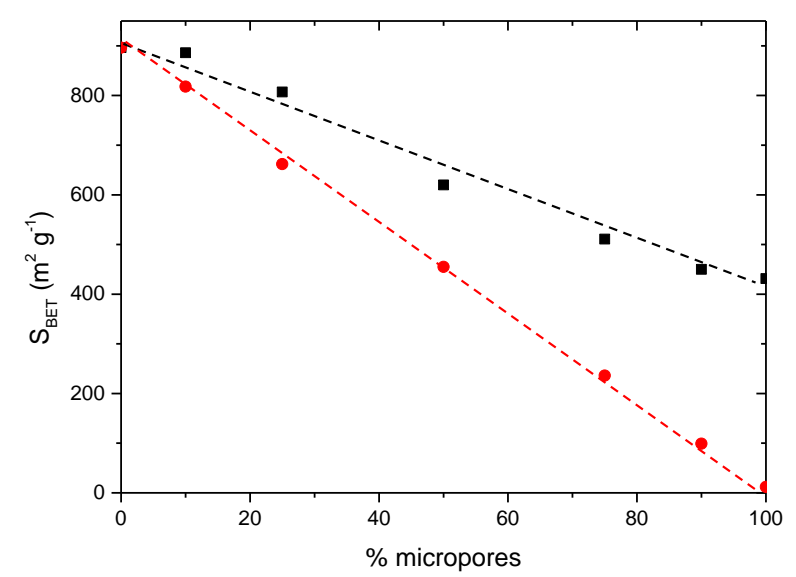

Figure 4. BET surface area calculated from the nitrogen adsorption isotherms at $77 \mathrm{~K}$ of mechanical mixtures M0, M10, M25, M50, M75, M90, M100 before (black) and after (red) $n$ nonane preadsorption.

Table 2. BET surface area of hierarchical ZSM-5 achieved by using $\mathrm{N}_{2}$ adsorption isotherms on usually prepared samples and through $\mathrm{N}_{2}$ adsorption on $n$-nonane preadsorbed samples.

\begin{tabular}{lcc}
\hline Sample & $\mathrm{S}_{\mathrm{BET}}\left(\mathrm{N}_{2}\right.$ adsorption), $\mathrm{m}^{2} \mathrm{~g}^{-1}$ & $\begin{array}{c}\mathrm{S}_{\mathrm{BET}}\left(\mathrm{N}_{2} \text { adsorption on } n \text {-nonane }\right. \\
\text { preadsorbed samples }), \mathrm{m}^{2} \mathrm{~g}^{-1}\end{array}$ \\
\hline M100 & 431 & 12 \\
NBM & 345 & 57 \\
SPM & 849 & 600 \\
HM-0.2 & 402 & 109 \\
\hline
\end{tabular}

Despite the striking advantages of this method, the $n$-nonane preadsorption is rather time consuming and difficult to implement as routine analysis to determine microporous volumes in laboratories. 


\section{4 $n$-Hexane physisorption to determine the exact microporous volume}

The adsorption of linear alkanes in zeolites has found major importance for the characterization of sorption kinetics in hierarchical systems. ${ }^{25}$ Measuring $n$-alkane adsorption isotherms with the scope to deduce textural characteristics of materials has found scarce interest. The sorption behavior of $n$-hexane has been described in ZSM-5, ${ }^{26}$ yet its use to determine textural key parameters of materials has so far not been put forward.

We performed the physisorption of $n$-hexane at $298 \mathrm{~K}$ on the mechanical mixtures M0, M10, M25, M50, M75, M90, M100 (Figure 5a). It is interesting to remark that the sorption of $n$ hexane occurs at lower relative pressures within the micropores than the adsorption on the external surface and on the mesopore surface. As these two adsorption phenomena fall into two well separated relative pressure ranges both mesoporous and microporous volumes can directly be quantified from the adsorption isotherm.

The occurrence of both processes at different relative pressure ranges can be rationalized by the stronger confinement of the $n$-hexane molecule within the micropores, which hence takes place at lower relative pressures compared to the adsorption of the probe on the external surface. Indeed the confinement of organic molecules leads to an important increase of their physisorption energy. ${ }^{27}$ This behavior has further been indicated in molecular simulation studies. $^{28}$

The microporous volume was obtained by extracting the adsorption capacity at the relative pressure of 0.001 . In order to calculate the microporous volume the apparent density of confined $n$-hexane of 0.623 was used, which was calculated from the mass of adsorbed $n$ hexane on M100 (0.0996 $\left.\mathrm{g} \mathrm{g}^{-1}\right)$, which is totally microporous and the microporous volume determined by $n$-nonane preadsorption experiments $\left(0.160 \mathrm{~cm}^{3} \mathrm{~g}^{-1}\right)$. The validity of this simple method was realized through plotting the obtained micropores volumes as a function of the theoretical microporous volume of the mechanical mixtures (Figure 5b). 

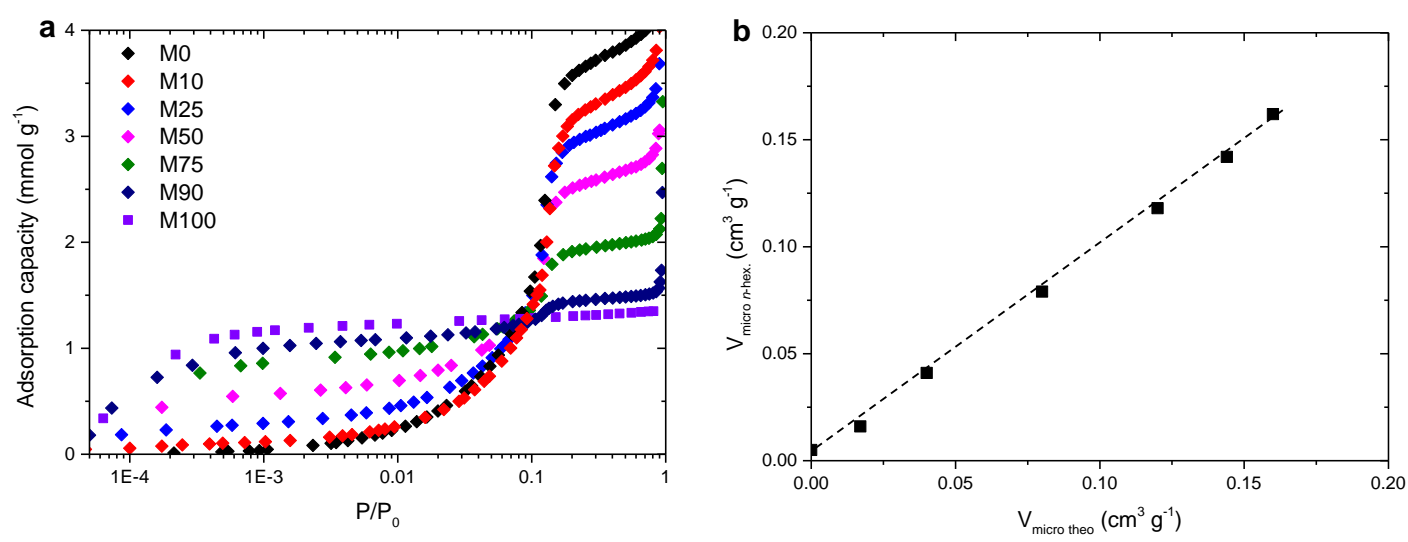

Figure 5. a) Adsorption isotherms of $n$-hexane at $298 \mathrm{~K}$ for the mechanical mixtures M0, M10, M25, M50, M75, M90, M100. b) Observed microporous volume at $\mathrm{P} / \mathrm{P}_{0}=0.001$ as a function of the theoretical microporous volume.

$n$-Hexane adsorption isotherms were further recorded on the hierarchical ZSM-5 samples (Figure 6). As far as the ZSM-5 nanoboxes (NBM) are concerned the microporous volume was determined to be $0.127 \mathrm{~cm}^{3} \mathrm{~g}^{-1}$. For the self pillared zeolite (SPM) the $n$-hexane isotherm does not achieve a plateau, which indicates, that in this sample the presence of a vast pore size distribution, comprising supermicropores and very small mesopores are present. Yet zeolite structured microporosity was found to be $0.094 \mathrm{~cm}^{3} \mathrm{~g}^{-1}$ at the relative pressure of 0.001 , which matches the microporous volume inferred from $n$-nonane preadsorption experiments. As far as the samples HM-0.2 and HM-0.6 are concerned, microporous volumes of 0.135 and $0.110 \mathrm{~cm}^{3} \mathrm{~g}^{-1}$ are observed, which again confirm the quantities of micropores calculated through $n$-nonane preadsorption experiments. We can hence deduce that the interpretation of the volume at the relative pressure of 0.001 corresponds to the exact microporous volume in $n$-hexane adsorption isotherms for ZSM-5 zeolites. 


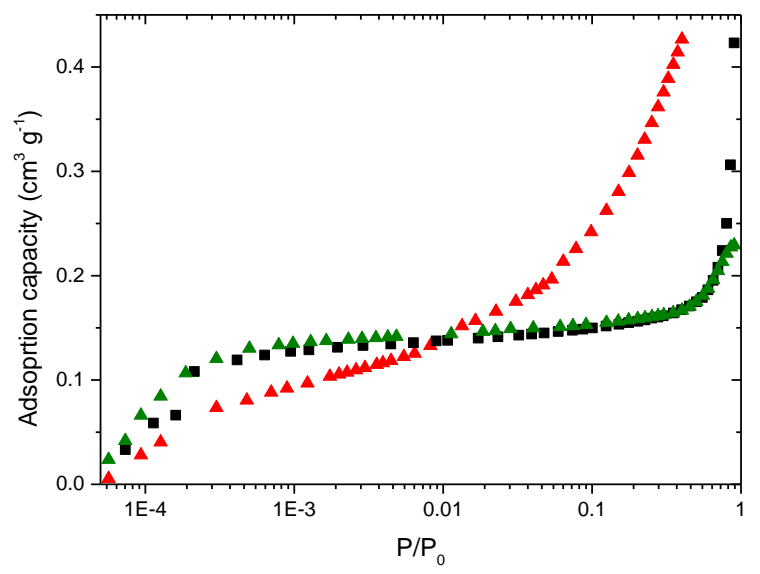

Figure 6. $n$-Hexane adsorption isotherms of NBM (black), SPM (red) and HM-0.2 (green) at 298 K.

\section{Conclusion}

Both the comparison of nitrogen adsorption isotherms at $77 \mathrm{~K}$ before and after $n$-nonane preadsorption and $n$-hexane adsorption isotherms allow for the diligent determination of the microporous volume in hierarchical ZSM-5 zeolites. The $n$-nonane preadsorption technique is more time consuming yet allows for the determination of the exact microporous volume through: ( $i$ ) the difference in adsorbed volume at the relative pressure of 0.4 and (ii) through the quantification of the amount of the adsorbed $n$-nonane. The $n$-nonane preadsorption strategy further allows for calculating the exact BET surface area, as the real monolayercapacity even for samples that contain small micropores can be inferred. The realization of $n$-hexane adsorption isotherms allows for the determination of the exact microporous volume as the adsorbate is strongly confined within the micropores and hence occurs at a relative pressure lower than that for the adsorption of the sorbate on the external and mesopore surface. Measuring $n$-hexane adsorption isotherms at $298 \mathrm{~K}$ is a fast and simple strategy and is promising to be used routinely in research laboratories for the accurate determination of the microporous volume in hierarchical systems. 


\section{ASSOCIATED CONTENT}

\section{Supporting Information}

Characterization of hierarchical zeolites through TEM and XRD, $\mathrm{N}_{2}$ adsorption and desorption isotherm of reference materials and generation of the $t$-plot for the reference nonporous silica is available as supporting information.

\section{ACKNOWLEDGMENTS}

The authors acknowledge financial support from the European Union (ERDF) and "Région Nouvelle Aquitaine".

\section{REFERENCES}

1. Derouane, E. G. Zeolites as Solid Solvents. J. Mol. Catal. A Chem. 1998, 134, 29-45.

2. Hartmann, M.; Machoke, A. G.; Schwieger, W. Catalytic Test Reactions for the Evaluation of Hierarchical Zeolites. Chem. Soc. Rev. 2016, 45, 3313-3330.

3. Pérez-Ramírez, J.; Christensen, C. H.; Egeblad, K.; Christensen, C. H.; Groen, J. C. Hierarchical Zeolites: Enhanced Utilisation of Microporous Crystals in Catalysis by Advances in Materials Design. Chem. Soc. Rev. 2008, 37, 2530-2542.

4. Sachse, A.; Garcia Martinez, J. Surfactant-Templating of Zeolites: From Design to Application. Chem. Mater. 2017, 29, 3827-3853.

5. Tanabe, K.; Hölderich, W. F. Industrial Application of Solid Acid-Base Catalysts. Appl. Catal. A 1999, 181, 399-434.

6. Cundy, C. S.; Cox, P. A. The Hydrothermal Synthesis of Zeolites: History and Development from the Earliest Days to the Present Time. Chem. Rev. 2003, 103, 663701. 
7. Meng, L.; Mezari, B.; Goesten, M. G.; Hensen, E. J. M.; One-Step Synthesis of Hierarchical ZSM-5 Using Cetyltrimethylammonium as Mesoporogen and StructureDirecting Agent. Chem. Mater. 2017, 29, 4091-4096.

8. Wei, Y.; Parmentier, T. E.; de Jong, K. P.; Zečević, J. Tailoring and Visualizing the Pore Architecture of Hierarchical Zeolites. Chem. Soc. Rev. 2015, 44, 7234-7261.

9. Mitchell, S.; Pinar, A. B.; Kenvin, J.; Crivelli, P.; Kärger, J.; Perez-Ramirez, J. Structural Analysis of Hierarchically Organized Zeolites. Nature Commun. 2015, 6, 8633-8647.

10. Verboekend, D.; Nuttens, N.; Locus, R.; Van Aelst, J.; Verolme, P.; Groen, J. C.; PérezRamírez, J.; Sels, B. F. Synthesis, Characterisation, and Catalytic Evaluation of Hierarchical Faujasite Zeolites: Milestones, Challenges, and Future Directions, Chem. Soc. Rev. 2016, 45, 3331-3352.

11. Galarneau, A.; Villemot, F.; Rodriguez, J.; Fajula, F.; Coasne, B. Validity of the t-Plot Method to Assess Microporosity in Hierarchical Micro/Mesoporous Materials. Langmuir 2014, 30, 13266-13274.

12. Groen, J. C.; Peffer L. A. A.; Pérez-Ramírez, J. Pore Size Determination in Modified Micro- and Mesoporous Materials. Pitfalls and Limitations in Gas Adsorption Data Analysis, Microporous Mesoporous Mater. 2003, 60, 1-17.

13. Thommes, M.; Kaneko, K.; Neimark, A. V.; Olivier, J. P.; Rodriguez-Reinos, F. Rouquerol, J.; Sing, K. S. W. Physisorption of Gases, with Special Reference to the Evaluation of Surface Area and Pore Size Distribution (IUPAC Technical Report). Pure Appl. Chem. 2015, 87, 1051-1069.

14. Lippens, B. C.; de Boer, J. H. Studies on Pore Systems in Catalysis: V. the t Method. J. Catal. 1995, 4, 319-323. 
15. Buttersack, C.; Möllmer, J.; Hofmann, J.; Gläser, R.; Determination of Micropore Volume and External Surface of Zeolites. Microporous Mesoporous Mater. 2016, 136, $63-70$.

16. Nakai, K.; Sonoda, J.; Yoshida, M.; Hakuman, M.; Naono, H. High Resolution Adsorption Isotherms of N2 and Ar for Nonporous Silicas and MFI Zeolites. Adsorption 2007, 13, 351-356.

17. Mentzen, B. F; Letoffe, J.-M.; Claudy, P. Enthalpy Change and Temperature of the Reversible Monoclinic-Orthorhombic Phase Transition in MFI Type Zeolitic Materials. Thermochim. Acta 1996, 288, 1-7.

18. Llewellyn, P. L.; Coulomb, J.-P.; Grillet, Y.; Patarin, J.; Andre, G.; Rouquerol, J. Adsorption by MFI-Type Zeolites Examined by Isothermal Microcalorimetry and Neutron Diffraction. 2. Nitrogen and Carbon Monoxide. Langmuir 1993, 9, 1852-1856.

19. Sing, K. S. W. Empirical Method for Analysis of Adsorption Isotherms. Chem. Ind. 1968, $1520-1521$

20. Gregg, S. J.; Langford, J. F. Evaluation of Microporosity, with Special Reference to a Carbon Black. Trans. Faraday Soc. 1969, 65, 1394-1400.

21. Carrott, P. J. M.; Conceicao, F. L.; Carrott, M. M. L. Use of n-Nonane Pre-Adsorption for the Determination of Microporous Volume of Activated Carbon Aerogels. Carbon 2007, $45,1310-1313$.

22. Grillet, Y; Llewellyn, P. L.; Kenny, M. B.; Rouquerol, F.; Rouquerol, J. Evaluation of the n-Nonane Preadsorption Method with a Well Characterized Model Adsorbent : Silicalite1. Pure Appl. Chem. 1993, 65, 2157-2167.

23. Brunauer, S.; Emmett, P. H.; Teller, E. Adsorption of Gases in Multimolecular Layers. $J$. Am. Chem. Soc. 1938, 60, 309-319. 
24. Rouquerol, J.; Llewellyn, P.; Rouquerol, F. Is the BET Equation Applicable to Microporous Adsorbents?. Stud. Surf. Sci. Catal. 2007, 160, 49-56.

25. Xu, D.; Swindlehurst, G. R.; Wu, H.; Olson, D. H.; Zhang, X.; Tsapatsi, M. On the Synthesis and Adsorption Properties of Single-Unit-Cell Hierarchical Zeolites Made by Rotational Intergrowths. Adv. Func. Mater. 2013, 15, 201-208.

26. Smith, B.; Maesen, T. L. M. Comensurate 'Freezing' of Alkanes in the Channels of a Zeolites. Nature 1995, 374, 42-44.

27. Derouane, E. G.; Andre, J.-M.; Lucas, A. A. Surface Curvature Effects in Physisorption and Catalysis by Microporous Solids and Molecular Sieves. J. Catal. 1988, 110, 58-73.

28. Bai, P.; Olson, D. H.; Tsapatsis, M.; Siepmann, J. I. Understanding the Unusual Adsorption Behavior in Hierarchical Zeolite Nanosheets, ChemPhysChem 2014, 15, $2225-2229$. 
TOC Graphic

Hierarchical ZSM-5: $\mathrm{V}_{\text {micro }}$ ?

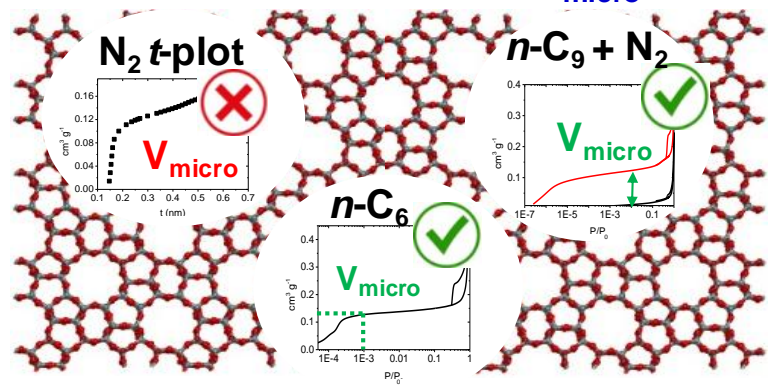

